It is of course no new idea that woollen, cotton and other fibres are two-phase systems at least. The elastic properties ${ }^{3}$ point directly to such a supposition.

Mercerisation makes changes in the X-ray picture; the spots move perceptibly, but very little, and the relative intensities of some of them alter. It would appear that the general form of the lattice remains much the same, but there is some slight rearrangement of the atoms in the unit cell, perhaps an addition to them. (The cellulose photograph shows, too, that there is more than one crystalline substance present.)

Artificial silks show the structure of cellulose, as might be expected ; though there are small differences in the intensities of different spots, depending on the

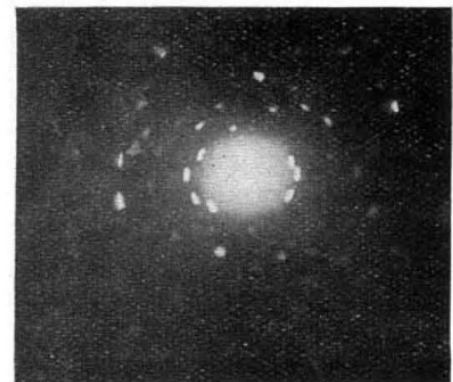

FIG. 5.-Spine of Arbacia. Laue photograph : rays heterogeneous, object held steady.

method of manufacture. Brill has examined a number of natural silks from different sources and found the same structure in all of them.

Herzog has examined chitin from various snails and insects, and found the same structure in them all. A very good spot diagram was obtained from a layer separated from the wing case of the Goliath beetle; the whole case, containing many layers, gave a blurred picture because the crystallites are not oriented the same way in the different layers.

In some cases the $\mathrm{X}$-rays have confirmed previous suppositions, as, for example, that the spines of the sea-urchin consist of single crystals, or at least of aggregates of single crystals all similarly oriented in all respects, not merely in one direction (Fig. 5).

These will serve as examples of the application of

3 Shorter, Journal of the Textile Institute, 15, 4, p. 207. the X-ray methods to various substances in the living organism. They are but a beginning, relatively few in number, and imperfectly understood.

In metallurgy the methods have been largely employed in the study of the gradual changes that take place during mechanical treatment. Rolling and drawing tend to give special orientations to the metal crystals. It has been shown by Wever, and by Owen and Preston, that in rolled aluminium foils the crystals finally arrange themselves so that (II2) planes lie in the surface, a (III) direction being the direction of rolling (Fig. 6). The cube diagonals of the small cubic crystals lie in the surface; this condition is satisfied

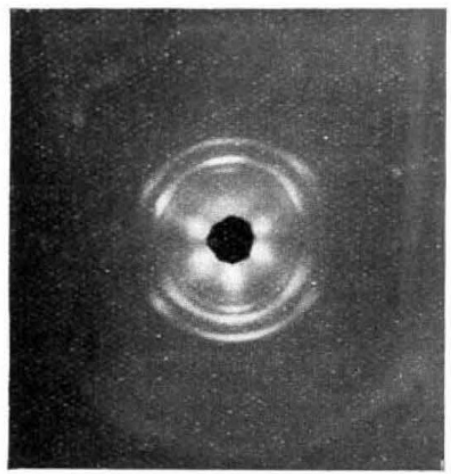

FiG. 6.-Aluminium foil rotated about an axis parallel to the direction of rolling $[\mathrm{x} i \mathrm{x}]$. Homogeneous rays.

by two positions of the cubes, which are images of each other in the surface.

The interesting point is that a certain tendency to orientation is a consequence of treatment which may be due either to mechanical handling or to some process of life. Absolutely irregular orientation cannot be generally consistent with purpose or design. Whenever small crystals exist in organic substances-and they are far more common than we have supposedtheir arrangement is connected with growth, and they may be essential to it, or illustrate it, or be connected with it in some way or other which may be important to know. The X-rays show simply and conveniently the amount of any such regularity, and it is for that reason that it is interesting to apply them to a wide study of natural structures of all kinds.

\title{
The Passing of Finsbury Technical College.
}

THE closing of Finsbury Technical Collegefamiliarly known as "Finsbury "--on July 26, after an existence of nearly half a century, is an event which will be generally regretted. The College was founded in 1878 by the City and Guilds of London Institute, its object being specifically to train students in the principles of science as applied to industry. In this respect it was a new departure in English education, and great interest in its future was aroused both in academic and industrial circles. The courses of instruction were in applied physics, mechanical engineering (to which civil engineering was added later), and applied chemistry, the first professors being W. E. Ayrton, J. Perry, and H. E. Armstrong. A department of applied art, under the direction of Mr. A. Brophy, was attached, and from the beginning both day and evening classes were held in all subjects. The experiment was immediately successful, and in $188_{5}$ the Central Technical College at South Kensingtonalso founded by the City and Guilds of London Institute -was opened. Profs. Ayrton and Armstrong were transferred to the new establishment, and were succeeded by Silvanus P. Thompson and R. Meldola, both of whom held office for more than thirty years.

Thompson on joining the staff was made principal of the College, and threw all his energy into the work. Under his direction the reputation of the College rapidly grew, and students were attracted not only from different parts of the British Isles, but also from all over the world. The day students attended for two years, and received the College certificate on passing

NO. 2960 , VOL. II 8$]$ 
the prescribed examinations. Special lecture and laboratory courses were arranged for evening students, many of whom made long train journeys to take advantage of the facilities afforded. No outside examinations were held, and within wide limits each member of the staff was permitted to teach what he thought best and most useful, instead of being tied down to an examination syllabus. Under this system Finsbury flourished, and the number of students increased to such an extent that further accommodation became necessary, and a new wing was added to the College in I904, which included a large engineering laboratory equipped with modern machinery and commodious drawingoffices. It appeared at this date that Finsbury was firmly and permanently established; but in the ensuing years various difficulties arose which threatened this seeming security, and ultimately led to the closing of the College.

The first troubles were financial. The amount available for Finsbury depended mainly upon voluntary subscriptions to the Institute from the City Companies, which were in some cases reduced in order to provide for special activities on the part of the companies concerned. The development of the College was greatly impeded by the absence of much-needed funds at a time when competitive establishments, often financed from public sources, were being organised in London and other parts of England. Temporary relief was afforded by the closing of the Art Department; but Finsbury was unable to keep so far ahead of its rivals as to attract a full complement of students from all quarters, and about I9Io a notable fall in the number of entrants, both day and evening, occurred. A contributory cause, in the case of day students, was the extension of the course to three years in order to conform with new regulations for admission to membership of the professional institutions.

At this stage the College also began to suffer from the increasing importance attached by public bodies, and even commercial companies, to the possession of a university degree, for which no provision could be made without fundamentally changing the character of the instruction. The War, with the greatly increased cost of upkeep which supervened, added further to the financial difficulties, and a great loss was sustained by the deaths of Profs. Meldola and Thompson during the War. In 1920 it was announced that the College was to be closed, and no new students were admitted in that year. As the result of a widespread agitation the
London County Council offered financial aid for a period of five years, and in I92I new students were again enrolled. The numbers joining, however, were not considered sufficient by the County Council to justify a continuation of the grant, and as the necessary sum was not forthcoming from any other source the closing of the College became inevitable.

Such, in brief, is the life-history of Finsbury; but a few words are needed to explain why it became well known all over the world. The two chief causes were an efficient and enthusiastic staff, from the principal down to the laberatory boys, and a true research atmosphere which infected the students and contributed largely to the great success they achieved in all branches of applied science. Amongst members of the staff who attained to the distinction of F.R.S. were the five early professors already named and Profs. Dalby, Coker, Morgan, and Eccles. Many important researches in applied science were carried out at Finsbury, such as the early work of Mrs. Ayrton on the electric arc; of Ayrton and Perry on electrical measuring instruments; Thompson on X-ray targets, cathode rays, and various electrical and optical devices ; Meldola on dye-stuffs; Dalby on the balancing of engines ; Coker and Scoble on the optical method of investigating stresses in materials and on the temperatures prevailing in the cylinders of internal-combustion engines ; and Eccles on various radio devices, including the valve-controlled tuning-fork.

All these researches were fundamental, and will in themselves preserve the name of Finsbury; but a much longer list could be compiled dealing with researches in many branches of physics, engineering, and chemistry conducted by other members of the staff. It will no doubt be possible easily to distribute the students who would have attended Finsbury among other institutions, but it will not be easy to establish everywhere they may go the atmosphere of enthusiastic work and inquiry which characterised the College and brought out the best that was in the students. It has been said that the usual fate of successful reformers is to render themselves superfluous ; and Finsbury, which set out to reform technical education and succeeded, has had this fate forced upon it by adverse circumstances. Whilst its demise must be deplored, it will be a satisfaction to all who have been connected with the College in any capacity that it has made for itself a lasting name in the annals of British education.

C. R. D.

\section{The Oxford Meeting of the British Association.}

$\mathrm{O}^{\mathrm{x}}$ $\mathrm{XFORD}$ is in many respects a centre well-suited for meetings of the British Association for the Advancement of Science. It is easy of access from most parts of the country; it is well provided with accommodation for persons with moderate requirements; it is situated in a neighbourhood full of interest both historical and natural ; and lastly, in its University lecture-rooms and laboratories it is able to furnish most of the conditions needed for the scientific business of the various sections.

In one particular Oxford is at a disadvantage compared with many of the places which have extended their hospitality to the Association-it is deficient in buildings large enough to collect all the members attending the meeting under one roof. It will not be possible in Oxford for even half of those who wish to do so to see and hear the Prince of Wales deliver his presidential address in his own person. The largest hall in the University - the Sheldonian Theatre-will not accommodate more than about ${ }_{5} 500$, and of these the large majority will have to submit to the discomfort of seats without backs. Conditions in the Town Hall, which has been put at the disposal of the Association by the civic authorities, are somewhat better adapted for an audience with present-day notions of comfort; though it will accommodate no larger number than the

No. 2960 , VOL. I I 8] 